\title{
The NeW Organization BASED ON KNOWLEDGE AND COMMUNICATION
}

\author{
KurtuhuZ, A.M. ; SAlisteanu, C.; Udroiu, I.; Petrescu, M.; \\ ISSA, C.\& UDROIU, F.
}

Abstract: Since ancient times, wealth and power were associated with natural resource possession. Traditional factors of production - land, machinery, buildings, etc. - Physical nature prevailed. Therefore, the need for comprehensive and in-depth knowledge was limited, transmission and their communication was impossible in their absence. The industrial revolution of the last centuries was based predominantly on steam power, man's physical strength and monetary capital. Wealth and power in this century will be the prerogative priority intangible intellectual resources, the knowledge and the power pack such communication to others. Exchanges and clear differences in the economic disruptions caused in the communication. Today we are witnessing the first stages of the knowledge revolution. Products and services, in terms of knowledge and communication are more intensive.

Key words: management, communication, knowledge, decision
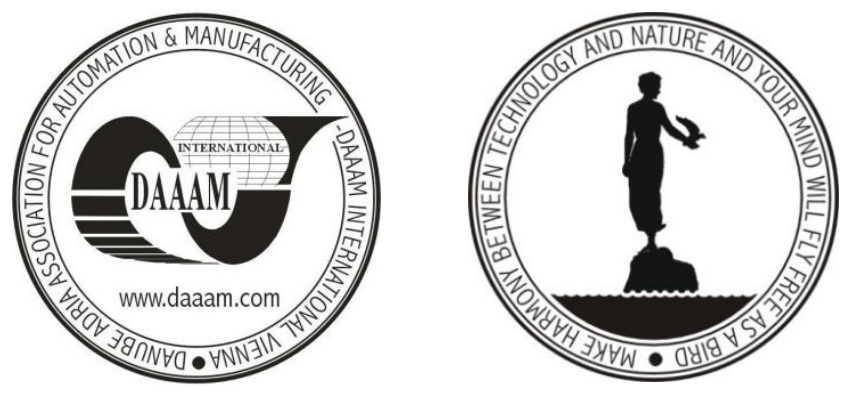

Authors' data: As. Univ. Dr. Ec. Kurtuhuz, A[ndreea] M[aria]; S.l. Univ. Dr. Ing. Salisteanu, C[orneliu]; S.1. Univ. Drd. Ing. Udroiu, I[ulian]; Prof. Dr. Petrescu, M[arius]; As. Univ. Drd. Issa, C[ristina] \& As. Univ. Drd. Udroiu, F[lorina]; University of Valahia, Bd.Carol I, No.2, 130024, Targoviste, Dambovita, Romania; andreea.kurtuhuz@yahoo.com, rvalahia@yahoo.com.

This Publication has to be referred as: Kurtuhuz, A[ndreea] M[aria]; Salisteanu, C[ornel]; Udroiu, I[ulian]; Petrescu, M[arius]; Issa, C[ristina] \& Udroiu, F[lorina] (2014). The New Organisation Based on Knowledge and Communication, Chapter 16 in DAAAM International Scientific Book 2014, pp.189-196, B. Katalinic (Ed.), Published by DAAAM International, ISBN 978-3-901509-98-8, ISSN 1726-9687, Vienna, Austria DOI:10.2507/daaam.scibook.2014.16 
Kurtuhuz, A. M.; Salisteanu, C.; Udroiu, I.; Petrescu, M.; Issa, C. \& Udroiu, F.: T...

\section{Introduction}

We said that the concerns of interpersonal communication plan, aesthetic on which have some degree of permanence, going a long time ago, some even up to the dawn of civilization.

Incipient elements of theoretical thinking in this area arise from the invention of writing, its pioneers are experiencing problems seeing the transformation language code type articulated vision.

Knowledge revolution, which consists of the transition to the knowledge based economy is therefore a complex process, giving changes in the essence of all components of an economic activity, analogous to the intensity of the industrial revolution ( Drucker, 1988). One area where the change from natural resource-based economy based on knowledge economy has brought many changes and is the communication.

Many exchanges and differences in the economic area caused the development of the communication. Today we live the first steps of the knowledge revolution. In terms of knowledge and communication, the services and the products are more intensive. Because of this, and the definition of these products and services is increasingly difficult to do.

\section{Communication management}

The concern about communication functions is very old, being connected, first, the name of Aristotle (384-322 BC) and having as its reference rhetoric; consider this first classification political function / deliberative (establishing the discourse of opportunity / inexpediency public action) function forensic / judicial (proving fairness / unfairness of acts committed) and function demonstration (praising / blaming a personality, highlighting an event, etc.) modern age exceeds the strict rigors of rhetorical discourse, research undertaken to establish communication functions based, in most cases, the analysis of the components of the communication process. Thus, Karl Bühler considers communication as "expression" in relation to the transmitter, as "representation" in relation to the message and the "call" in relation to the receiver, thus distinguishing three functions: expressive, representative and appellations.

It is interesting to note that there is here an analogy with radio transmission - a new technique of time - from which the words are taken and the transmitter, message, receiver, now established in terms to which we refer.

Twenty years later, this issue is taken up by Roman Jakobson and M. Halle (Fundamentals of Language, 1956), which call for a more nuanced approach by making a distinction between form and content of the message and the introduction of new elements in the discussion of the process communication: the code and the transmission channel. In this way, the area is extensive communication functions they reached six, namely: 
1) The expressive / emotive, highlighting the emotional states of the transmitter, its reactions to a particular stylistic reality expressed by various means, interjections, verbal forms, specific expressions, etc.

2) The poetic, given message, is how it is expressed, the attention being focused on the signifier receptor with its poetic or graphic, in this case it is privileged and not subject to the actual situation of communication.

3) The connotative / persuasive / rhetorical, given receptor which is expected to obtain a certain side of a certain response in the desired transmitter by using certain interjections, a certain verbal forms (imperative) etc.

4) The metalinguistic function, manifested when it is necessary to report the code that makes communication and which finds expression in gestures, tone, explanatory circumlocutions, etc.

5) The phatic function, referring only to the characteristics of the communication channel and control its functioning without any connection to the communication partner with the message sent or used. Although contested by other researchers, this function can be recognized in numerous verbal or non-verbal signals that manifest especially in interpersonal communication, such as greetings, gestures of approval, disapproval, eye contact, etc.

6) The referential, besides aiming message reference and context, situational context in which communication takes place. This latter function can give rise to various interpretations, is somewhat ambiguous, was revealed by Dell Hymes (On Communication Competence, 1972), which in addition to the explicit recognition of a proper referential functions centered on the topic of communication, proposes a seventh position, the contextual / situational; This function takes into account the context of the communication, is the situation in which it is conducted. It is important to note that Jakobson pointed out that these features of the language that we consider, but are taken into account when speaking of communication, coexist in the act of speech, differing only in the order hierarchical structure of the message depends on the function word prevalent.

The problem of communication functions continued to interest researchers; thus, Ronald Adler and George Rodman addresses the communication functions, treating them in terms of those needs of the human being which is manifested through communication and are of the highest importance to the individual. It speaks necessities such physical, psychological, social, and practical. Communication is an essential function in existence, maintenance and development of personal relationships between individuals, which determines their normal development and according to the latest studies - adequate physical health status, allowing basically survival of the species.

As a result of interaction between individuals through communication to obtain "sense of identity" to each of them; ascertain who and what we are, based on the reaction of others towards us in the communication.

All communication is done through the social bond between individuals. In this regard, W. Schutz (The Interpersonal Underworld, 1966) describes three types of needs met through social communication: inclusion - a sense of belonging to a group; 
control - the desire to influence or exert power over others, either directly or subtly; disease - need to share feelings with others. Finally, the practical communication meets our needs, from those related to daily activities, to the most sophisticated. In addition, to complement these features, we can refer to Abraham Maslow (Toward a Psychology of Being, 1968), which includes the category "of needs" achieved through communication "self-assessment" - the desire to develop personal capacity to the maximum, to become superior to ourselves.

\section{Knowledge management}

Knowledge has become the main feature start of many activities, rather than products or services obtained. The influence of this revolution volatilatea knowledge becomes visible in the market, uncertainties regarding directing economic activities, change in the structure value and product prices, product proliferation symbol, uncertainty in terms of careers and jobs people felt.

The result of the knowledge revolution is the knowledge-based economy. It is estimated that in the first revolution of the XXI century knowledge will increase and as a result, the knowledge economy will expand rapidly in the humanity and gradually developed into the other (Drucker, 1992) .

Today, we can send and receive information immediately, anywhere in the world. Due to this fast, verification of information is becoming increasingly difficult for both journalists and the public. Communication is essential, but you need to compare and look with a critical eye all the information we receive.

With the book, the information can be received by many people. Today, the books are produced in large numbers and are easily transportable. But first books were far from fulfilling these conditions.

Today, information is transmitted through multiple carriers, depending on the amount of information to be conveyed, the transmission speed and distance. The telephone communication can flow through the wire to a local, then be mounted on the air to a satellite or cable oriented to cross the ocean to complete its route as on.

Researchers develop new communication technologies in a bid to improve the multimedia tools are used by more people. The research aimed to achieve miniaturization and mobility simplify the use of these technologies. Technological research led to the miniaturization of electronic assemblies have created computer systems becoming smaller and therefore more easily transportable. The portable unit can be equipped with CD Rom, modems and mobile phones . Thus we can easily call, can send and receive faxes, or can browse the Internet anywhere in the world. Thus, we remain in constant contact with our place of work or with family members. A device PDA (Personal Digital Assistant - personal digital assistant ) is a real central wireless communication. It combines the functions of the electronic book, the telephone directory, word processor, Minitel network, the fax and email. All data recorded on the PDA can be transferred to a computer system . Sure it will soon be on sale and other mobile devices . Researchers are working, for example, the development of flat screen TV and thin, with a thickness of only a few 
millimeters . Similar screens portable pocket size books will facilitate direct loading of newspapers or novels laptops .

The research is oriented towards the decommissioning of the mouse, a keyboard or a data glove in order to give instructions directly. Touch screen ( touch -screen) now facilitate the communication with the computer with a simple touch of your fingertips certain portions of the screen. Some computers we can verbally command multiple functions of a program or can dictate text directly. This technique is very useful for the disabled. Recent cameras settings and camescoapelor can be ordered directly through the eye : the image automatically secures the area where the user viewed .

Some researchers are trying to develop programs that allow computer control through thought. Helmets pilots on fighter planes have visors receiving information directly from the onboard computer. The information is displayed in the pilot's field of vision. Some headsets capture brain waves, which allows faster onset shooters during aerial battles .

The transmission of digitized information can jump from one human body to another, through an easy contact . It is the discovery researchers at the Massachusetts Institute of Technology (Boston, USA), which use natural electrical conductivity of the human body. Data transmitted, the name and address our newspapers etc . are listed on an electronic card memory ( realized by IBM ). When two people who have such cards touch, computer data are automatically transmitted because electricity crossing the body . However, the process is relatively slow (400,000 bits / second), but he could replace small appliances such as PDAs communication. In addition, this technique will allow direct communication between the card holder and a device adapted (car, phone etc. . ) .

Communication is a specific human action aimed to decipher the meaning, significance, connotation and denotation of social links (Palmer 1988), organized and disorganized, with symbols of signs, representations and other ways of modeling information in order to trigger, achieve stability, gain, reduction, postponement or halting of individual and group behaviors.

Communication is always done with the intent to influence the quality, not just quantity. It is not by transfer of qualities. Communication is the set of processes that are sharing different information and meanings between individuals are in a certain social situation. Communication between authors involved facilitates the flow of information for their interaction in the form of various languages, to achieve the objectives of the Community. Other researchers believe that communication process consists of all the operations of sending and receiving symbols with meanings attached to them.

Communication - as a function of management - include complex issues related to the process of change, not only in internal communication with employees but also external communication, national and international, with customers, suppliers, investors or any group that has an interest in terms of organization (Gamble,1993).

Any communication involves interaction. It is presented as a dynamic phenomenon involving a transformation, being subsumed under a process of influence between multiple stakeholders. Thus, we are in the presence of a transmitter and a receiver, but the two parties. Communication is, therefore, a social act, intentionally or unintentionally, consciously or not. It is in any case one of the acts 
underlying the social bond. The whole process can not be conceived unless considering two poles: the transmitter and receiver. Bipolarity can be conceived as another feature of the communication process.

The organization, the transmitter is the receiver must adapt choosing the signs of the system (para ) linguistic partner knows you, preferring some values known that he understood. It follows therefore a new feature of communication - adaptability. What is noteworthy is that, by submitting an effort of adaptation, are influenced by the receiver coil (Stiglitz,1999). In turn, however, the receiver must adapt the message was sent, making an effort to know the coordinate system represented by the transmitter, the values assigned by subjective signs him.

Adapting partners is mutual interest in making communication efficiency. Especially in interpersonal communication, roles transmitter / receiver are reversible and complementary, each of the two subjects can operate as transmitter and receiver, influencing each other (Palmer, 1998). These actions occur simultaneously, at least in the non - verbal, which makes each person is influenced, on the one hand, the messages that they receive around it, and on the other hand, the effects of your posts the party's conduct. Thus we can refer to another feature of communication bilaterality ( reversibility ). The importance of this feature is illustrated by the interactive nature of communication that any act implied, although in some cases ( group communication, remote) appear less prominent .

There is ignored flexibility as a feature of the partners in the communication process. At the same time, establishing a permanent, ongoing communication has some beneficial results for the expression of interlocutors and communication itself (Stewart, 1998). Prolonged time communication lead to the installation of a uniform cognitive level, in terms of attitudes and behaviors exhibited, individuals continue then to influence each other to maintain this consistency .

Another aspect to note is that the behavior or words of communication partners can extract some attitudes, motivations lead to the belief that the person can transmit what he wants, when he wants and in their own way. In other words, there is a certain intent, it constitutes, moreover, a new feature of communication. In general terms, a message can be sent from the transmitter to another person - the receiver when the transmitter is considered as a possible source of satisfaction through mutual understanding of information (Romer, 1998). Therefore, the transmitter acts as their objectives would be grateful if he and the receiver have, after sending the message, the same information. Equalization of information is thus a way of relationship between the transmitter and receiver giving a means of meeting the various necessities. Anyone who communicates directly involved in the situation of communication, engaging in it with his personality and needs its own system that determines motivations.

\section{The importance of communication and knowledge management}

In today's economic climate, this puts great emphasis on information; organizations get the most value from their property intellectual rather than the physical ones (Hellström, 2000). Knowledge management helps to keep the knowledge to be distributed to the foundations of collaboration. In addition, knowledge management helps organizations in the following aspects: 
- Supporting innovation. Knowledge Management provides an infrastructure for electronic and social networks so that they can develop new products or services; it supports and provides access to sources of ideas, because they can be transformed into capital.

- Supporting collaboration. Knowledge management enhances opportunities for collaboration; it enriches the tacit and explicit knowledge sharing between people; and encourages the free flow of ideas.

- Encouraging learning and use. Knowledge management facilitates and accelerates the learning process; it creates opportunities for individuals and groups to implement new knowledge; He exploits the organizational knowledge and bring appropriate knowledge to reach the right people in an understandable context explaining new challenges; He recovered by rewarding individual learning and speculating advantage derived from the entire organization.

- The development of social capital. Knowledge management enhances individual knowledge transfer within the organization; He supports the exchange outside the organization, the time and space; and put together people who hold tacit and explicit knowledge needs to people who need this knowledge to perform their work.

- Attracting and retaining human capital. Knowledge management improves retention rates according to employees by recognizing the value of each employee's knowledge and rewarding him / her for this stock of knowledge; captures and leverages what people know - that 'know how' and 'know why'; promote career development.

- Create and use structural capital. Knowledge management transform intellectual capital into structural capital; and directs strategic thinking towards knowledge capitalization above focus on budget issues.

- Increase productivity. Knowledge Management streamlines operations and reduces costs, risks, learning curves and initialization times by eliminating redundant or unnecessary processes; it contributes to the fundamental goals / mission.

- Sharing best practices / processes. Distributed knowledge management best practices throughout the organization; it learns from failed efforts; provides a platform for innovation and knowledge reuse; establish reference points for internal and external performance of individuals and teams; and help new employees to familiarize themselves quickly with the organization's culture.

- Providing leading authority and decision-making capacity. Knowledge management provides the right information in a context that supports decision making; it integrates new knowledge into decision-making processes through the exchange and cooperation with the scholarship players and temporary agents in decision-making processes; and use information and knowledge for harmonizing the actions of organizational missions and visions.

- Increasing customer satisfaction. Knowledge management improves customer service by streamlining response times; it focuses on knowledge of customer 
Kurtuhuz, A. M.; Salisteanu, C.; Udroiu, I.; Petrescu, M.; Issa, C. \& Udroiu, F.: T...

needs to drive the efforts of an organization; and improve customer experiences and results regarding the services that are provided.

- Establishing a distinction between competitive advantage and business market. Knowledge management helps to ensure knowledge superiority; when it takes the form of a proposed business, products or services, the amended proposal for recovery from providing goods and services at providing knowledge and expertise for these goods and services; organizational and collective.

\section{References}

Drucker, P. (1988) - The coming of the new organization. Harvard Business Review, 66(1) : 45-53

Drucker, P. (1992) - The new society of organizations. Harvard Business Review, 70(5) : $95-104$

Gamble, T.K., Gamble, M. (1993), Communication Works, McGraw Hill, New York Hellström, T. (2000) - Knowledge and competence management at Ericsson: decentralization and organizational fit. Journal of Knowledge Management, 4(2), 99-110

Hymes, D.H. (1972) On Communicative Competence In: J.B. Pride and J. Holmes (eds) Sociolinguistics. Selected Readings. Harmondsworth: Penguin

Jakobson, R., Halle, M. Fundamentals of Language (1956), https://archive.org/ stream/fundamentalsofla00jako/fundamentalsofla00jako_djvu.txt, Accesed on: 2014.09.07

Palmer, J. (1998) - The human organization. Journal of Knowledge Management, 1(4) : 294-307

Romer, P. (1998) - Two strategies for economic development: using ideas and producing ideas, In "The strategic management of intellectual capital" (D. Klein ed.), Butterworth-Heinemann, London : 211-238

Schutz, W. The Interpersonal Underworld, (1966) Palo Alto, Calif : Science and Behavior Books

Simonsen, Jesper (Spring 1994). "Herbert A. Simon: Administrative Behavior. How Organizations Can Be Understood in Terms of Decision Processes". Roskilde University. http://jespersimonsen.dk/Downloads/Simon-introduction.pdf. Accesed on: 2012.05.11

Stewart, Th.A. (1998) - "Intellectual Capital. The New Wealth of Organizations", Nicholas Brealey Publishing, London

Stiglitz J. (1999) - Public Policy for a Knowledge Economy. Remarks at the Department for Trade and Industry and Center for Economic Policy Research, London, U.K., January 27, 1999 (www.worldbank.org/html/extdr/extme /jssp012799a) Accesed on: 2014.07.14 